\title{
TEST RESULTS FOR ROTORDYNAMIC COEFFICIENTS OF ANTI-SWIRL SELF-INJECTION SEALS
}

\author{
C.H. Kim and Y.B. Lee \\ Korea Institute of Science and Technology \\ Seoul, Korea
}

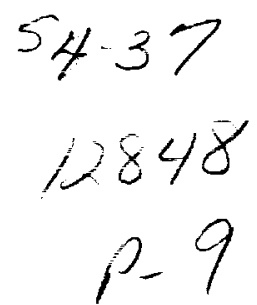

Test results are presented for rotordynamic coefficients and leakage for three annular seals which use anti-swirl self-injection concept to yield significant improvement in whirl mechanism is achieved by deliberately and damper seals. A new anti-swirl self-injection to partially divert inlet flow into the anti-ing self-injection holes inside the seal stator mechanism is used to achieve effective reductioction. The anti-swirl self-injection considered as a prime cause of rotor instability in hion of the tangential flow which is results show that the self-injection mechanism significantly improves turbomachinery. Test mechanism. leakage performance degrades due to the introduction of frequency ratios; which uses. Through a series of the test program, an optimum anti-swirl the self-injection significant impyrinth stator surface with anti-axial flow injections is self-injection seal significant improvement in the whirl frequency ratio as injections is selected to obtain a showing moderale leakage performance. compared to a damper seal the optingection with a labyrinth surface configuration. When by a factor of 2 .

\section{NOMENCLATURE}

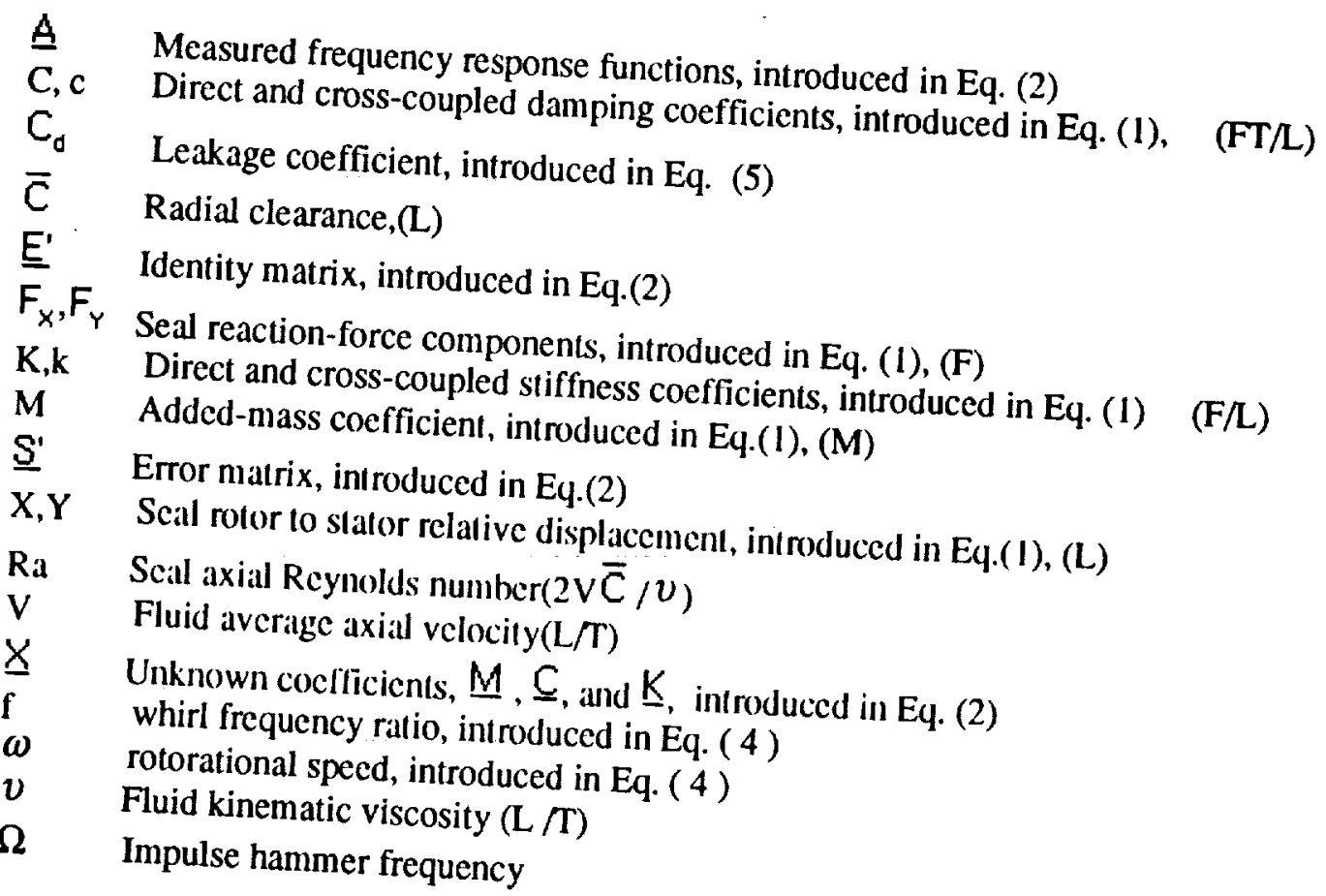




\section{INTRODUCTION}

Throughout 1980's, one of the major concems in seal dynamics is the consequence of a reduction in the tangential velocity inside the seal. Lower tangential velocitics yield a reduction in the cross-coupled stiffness coefficient $k$ of the following reactionforce/displacement model for the seal.

$$
-\left\{\begin{array}{l}
F_{X} \\
F_{y}
\end{array}\right\}=\left[\begin{array}{ll}
K & K \\
-K & K
\end{array}\right]\left\{\begin{array}{l}
X \\
Y Y
\end{array}\right\}+\left[\begin{array}{ll}
C & c \\
-C & C
\end{array}\right]\left\{\begin{array}{l}
\dot{X} \\
\dot{Y}
\end{array}\right\}+M\left\{\begin{array}{l}
\ddot{X} \\
\ddot{Y}
\end{array}\right\}
$$

This lincarized model is assumed to apply for small motion about a centered position and defines the reaction-force components $\left(F_{x}, F_{y}\right)$ in terms of $(X, Y)$, the components of the displacement vector of the seal rotor relative to its stator. Reducing $k$ reduces the destabilizing forces developed by the seal due to hydrodynamic action and should yield a higher stable operating speed for pumps. von Pragenau(1982) originally proposed that annular seals for pumps which used rough
stators and smooth rotors would lower tangential velocities than conventional seals which use smooth rotors and stators. A reduction of the tangential velocity was realized through damper seals(Childs and Kim, 1985,1986; Iwatsubo and Sheng,1990) which used rough stators and smooth rotors. The surface-roughness pattem retards the generaton industrial applications inside the seal clearance. While damper seals are adoplemative in reducing the tangential into high performance turbomachinery, a promirl brake". The swirl brake which is used in velocity is introduced and tested, name brakes the inlet swirl inherent inside the seal the inlet section of the seal clearance ben reported with a sucess in the SSME HPOTP clearance. The related rescarch effor heals. (Childs et.al,1990)
turbine interstage seal

In this paper, a 'new' concept in reducing the tangential velocity is proposed and preliminarily tested with a series of the seal. Newly proposed is the anti-swirl self-injection scal which is illustrated in Fig. 1 along with smooth and damper seals for comparisons. Using the inlet high pressure, the inlet flow is partially diverted into holes or slots inside the seal stators and self-injected into the reverse direction of the shaft rotation. This concept can be a more aggressive measure to a reduction of the tangential flow inside the seal clcarance. The resultant tangential velocity is presumably reduced, and the consequent improvement in stability can be obtained. This anti-swirl self-injection concept is showamines the process of alternative to the conventional swirl brake. The presenty proposed seals. The consequence of the the concept realization and refinement investigated.

\section{TEST APPARATUS}

A new test rig was designed and built, based on the basic design reported in the reference of Massmann and Nordmann(1985). The principle of the test rig is simple but complicated enough to satisfy the current purpose of the test. Fig. 2 illustrates the test re The the test rig. The two identical seal inserts can be exchanged for new test seals. After the seal is inserted into the main housing, the pressure measurement holes are machined and connected to the Scani-valves. With a four stage supply pump and controlled flow rales, the supplied fluid enters the seal section in the middle through two supply holes. The inlet fluid then exits through two seal sections. The magnetic flow meter measures flow rates in the exit pipe line. The pressurized seal generate the seal forces which are the source of the dynamic coefficients. The movement of the main body relative to the rotor was measured by four eddy-current-type proximity probes. As will be explained later, seal coefficients can be measured with dynamic impact tests for each test seal. 
The temperatures, flow rates, and pressures are measured and controlled through a personal computer.The temperature of the working fluid, water, was kept constant at $40^{\circ} \mathrm{C}$, using an Massmann and Normann(1985) is the the water tank. A modification to the apparatus of clearance through the Scani-valve mechanisn illustat of the static pressure inside the seal pressure readings inside the seal clearance, and the outlet in Fig. 3. The inlet pressure, five Scani-valve mechanism which is connected to a pressure sensor.

With this test rig a test matri

pressures up to 10 bars. Five seal inserts were sequentially speeds up to $6000 \mathrm{rpm}$ and supply and supply pressures.

\section{TEST SEALS}

As stated in the preceding section, five seals were tested serially for concept demonstration and refinement of the newly proposed seals. For comparison to conventional seals, a smooth seal, and three anti-swirl self-injection seals. The geometries of a smooth seal, a damper from the test results in the reference of Childs and damping. For the anti-swirl pattem, a 12 holes injection (1986) for a possible optimum holes were drilled into the stator body and then the anti-swirl pattensidered. Twelve supply injectionst the direction of rotation. For leakage reduction, 6 as realized by drilling seals. All tested labyrinth surface were considered. Table 1 shows, a 6 degree anti-leakage Details arested seals have the same minimum clearance of 0.2 the configuration of tested configure explained in the table. Seal 3 was tested first to $2 \mathrm{~mm}$ with a smooth rotor. configurations. The effect of anti-leakage injection was tested in the effect of anti-swirl anti-swirl injection. Based on the above scries of tested seals, in seal 4 with 12 holes of anti-leakage injection and labyrinth effect was tested.

\section{SEAL PARAMETER IDENTIFICATION}

The impulse hammer technique was used for the dynamic testing of the parameter 4. As explained in detail in the reference of Masmand Nomann, 1985) as illustrated in Fig. variable method is used. In conjunction wassmann and Nommann(1985), the instrumental variable method utilizes the measured frequency response fquare method, the instrumental algorithm for better curve-fittings.

Utilizing the fact that the product of the mobility matrix and the stiffness matrix should be the identity matrix, a complex equation is arranged into an overdetermined equation system in
the case of a broad band excitation of the impulse hammer.

$$
\underline{A X}=\underline{E}^{\prime}+\underline{S^{\prime}}
$$

where $A$ consists of the measured frequency respons frequencies $\Omega, \underline{x}$ represents the unknown response functions related to the exciter identity matrix and $\underline{S}^{\prime}$ is the error mannown coefficients $\underline{M}, \underline{C}$, and $\underline{K}, \underline{E}^{\prime}$ is a modified seal coefficients, the instrumental variable After deriving the Ioss function with respect to the matrix $\frac{W^{\top}}{}$ with instrumental variables is buill up usplied as shown in Fig. 5. A new original least square matrix method.

$$
\underline{W^{\top}} \underline{A X}=\underline{W}^{\top} \underline{E}^{\prime}
$$

As shown in Fig 5 , this procedure

compared with that of the last step. The repeated and after cach step the actual estimation is instrument variable method is less sensitive to nure stops if the correlation is satisfactory. The 
error of the identified coefficients(Massmann and Normann,1985) as illustrated in Fig.6.

\section{EXPERIMENTAL RESULTS}

\section{Dynamic Coefficient and Leakage Test Data}

For a given seal configuration, a test matrix is obtained by varying the axial Reynolds number and running speed. The Ra range varies between the maximum flow capacity of the supply pump and minimum $\Delta P$ sufficient to generate reasonable transient pressure signal amplitudes. For a given $\mathrm{Ra}$ value, the running speed is varied sequentially over the runningspeed capacity of the drive motor.

An evaluation of the relative performance of scal configurations is expedited by extracting stiffness, damping, and mass coefficients from the impact force/displacement data in frequency domain. From a stability standpoint, the destabilizing tangential force is of most interst. A positive cross-coupled stiffness $k$ is destabilizing because it drives the forward orbital motion of the rotor. Positive direct damping $\mathrm{C}$ and a negative cross-coupled stiffness are stabilizing because they oppose the orbital motion. A convenient measure of seal stability is the whirl frequency ratio of cross-coupled stiffness to direct damping forces with a circular orbit.(Childs et.al,1989)

$$
\text { whirl-frequency ratio }=\mathrm{f}=\frac{\mathrm{k}}{\mathrm{C} \omega}
$$

The stator inserts are to be evaluated based on $\mathrm{k}, \mathrm{C}$, whirl-frequency ratio, and leakage performance. Volumetric seal leakage is defined by

$$
\Delta P=C_{d} \frac{\rho V^{2}}{2}
$$

where the leakage coefficient $C_{d}$ is a nondimensional relative measure of the leakage to be expected from seals with different radii.

\section{Relative Uncertainty}

The uncertainty in the dynamic coefficients can be determined using the method described by Holman(1978). The uncertainty in the force and displacements are $0.5 \mathrm{~N}, 0.0016 \mathrm{~mm}$, respectively. Before normalization, the nominal calculated uncertainty in stiffness coefficients is $51.53 \mathrm{~N} / \mathrm{mm}(4.67 \%)$ and $0.164 \mathrm{~N}-\mathrm{s} / \mathrm{mm}(3.82 \%)$ for the damping coefficients. These predicted uncertainty values are generally satisfactory in comparison to nominal dynamic coefficients.

\section{Relative Performance of Anti-Swirl Self-Injection Seals}

As stated, relative performance of anti-swirl self-injection seals was compared with a smooth seal and a damper seal in terms of leakage and stability. The leakage performance was measured by the leakage coefficient, while the stability was measured by the whirl frequency ratio. The influence of rotor speeds on the direct damping and the cross-coupled coefficients was first examined for an axial Reynolds number 8,000 in Fig. 7. First, as expected, the direct damping is independent to the rotor speeds, while the cross-coupled stiffness is a strong function of the rotor speeds;viz. the current lest results follow general trends of other seals as predicted in the previous reports in references of Childs and Kim(1985,1986) and Iwatsubo and Sheng(1990). For the damping coefficient, the damper seal is outstanding ; nearly six times the smooth seal and trifold the anti-swirl self-injection seals. For the cross-coupled stiffness coeflicient. seal 5 outpertoms other seals; ten limes smaller than the smootl seal and twenty times smaller than the damper seal. The anti-swirl seli-injection 
seals have much smaller values than conventional seals in the cross-coupled stiffness. These tangential flow inside the seal clearance and coupled stiffnesses.

In Fig. 8, the whirl frequency ratio and leakage coefficients were compared among tested
scals. As expected in the are much better than the smooth seal of dynamic coefficients, anti-swirl self-injection seals best; more than six times less than the Among the anti-swirl self-injection seals, scal 5 is the as the leakage performance is concemed theoth seal and less than half the damper seal. As far test program, seal 3 was tested first and foumd damper seal outperforms the others. During the Therefore, the anti-axial flow pattem was introduced in too much leakage as shown in Fig. 8. $\%$ over the seal 3, while showing about the samed in the seal 4 . Seal 4 improves about 10 Results show that the anti-axial flow injection is performance in the whirl frequency ratio. reduction; maybe because of the limited revis not as attractive as first expected for leakage current test rig installation, or the sharp acuterse angle( 6 degree) due to the limit of the much of its momentum to have a discernible reverse turn make the diverted flow lose too this test series, seal 5 with labyrith effect is tested. The labyrinth concept. Finally, in improve the leakage performance; however, it was. The labyrinth effect was introduced to seal. More tests are planned for improving was not enough, compared with the damper importantly in stability view point, these test the leakage performance. However, more concepts clearly show that the anti-swirl concept is very effective in impming self-injection seal pressure differences. As the pressure difference increafficients are compared with different result follows general trends of other seals. The damper seal has the himping increases; this Seal 3 and seal 4 have $30-40 \%$ higher damping values than the smooth seal. Seal 5 has about
the same damping values as the smooth seal. For the self-injection seals show a clear pattem of . For the cross-coupled stiffness, the anti-swirl smooth and damper seals which show increased cross-coupled stiffnesses: versus the pressure difference is increased. The anti-swirl self-injection stiffness patterns as the constant cross-coupled stiffnesses. Again this self-injection scals show decreasing or injection concept.

In Fig. 10, the whirl frequency ratios and leakage coefficients are compared. As expected from Fig. 9, anti-swirl self-injection seals show clear superiority in stability performance frequency ratio; less than half that of smooth and performance can be a drawback. Seal 4 and seal 5 are better than . However, the leakage the damper seal leaks $20 \%$ less than seal 5 . These results show that better designs should be
addressed in the anti-swirl self-injection seals. Along with this dependency of pressure differences and hole numbers flong with this leakage performance, the be studied in more details. Current results demonstrate how the stability performance should perform and introduce the concept of anti-swirl and self-injection swechanismjection seals seals.

\section{CONCLUSIONS}

Newly proposed anti-swirl self-injection seals have been tested and compared with smooth and damper seals. Test results show that the anti-swirl self-injection concept can significantly whirl frequency ratio as compared with a w a stability improvement by a factor of 2 in the preliminary test is the leakage performance. More detailed test frawback identified in this based on new designs are planned and could solve this problem.

\section{REFERENCES}

Childs, D.W., Baskahrone, E., Ramsey. C., 1990" Test Results for Rotordyanmic Coefficients of the SSME HPOTP Turbine Intersatge Seal with Two Swirl Brakes," NASA 
CP 3122, Proceedings of the workshop : Rotordynamic Instability Problems in High Perforamance Turbomachinery held at Texas A\&M University, May 21-23, pp 165-178

Childs, D.W., Elrod, D. and Hale, K., 1989,"Annular Honeycomb Seals: Test Results for Leakage and Rotordynamic Coeficients; Comparisons to Labyrinth and Smooth Configurations," ASME Trans. Joumal of Tribology Vol. 111, pp293-301

Childs, D.W. and Kim,C.H., 1985,"Analysis and Testing for Rotordyanmic Coefficients of Turbulent Annular Seals with Different, Directionally Homogeneous Surface-Roughness Treatment for Rotor and Stator Elements", ASME Trans. Joumal of Tribology Vol. 107, No.3, July , pp296-306.

Childs.D.W. and Kim, C.H., 1986, "Test Results for Round-Hole-Pattem Damper Scals : Optimum Configurations and Dimensions for Maximum Net Damping," ASME Trans. Joumal of Tribology Vol. 108, Oct., pp605-611

Holman,J.P., 1978, Experimental Methods for Engineers, McGraw Hill, pp45

Iwatsubo, T., and Sheng, B.C., 1990,"An Experimental Study on the Static and Dynamic Characteristics of Damper Seals," Proceedings of 3rd International Conference on Rotordynamics, Lyon, France, Sept.10-12,pp99-104

Massmann, H. and Nordmann R., 1985," Some New Results Concerning the Dynamic Behavior of Annular Trubulent Seals," NASA CP 2409, Proceedings of the workshop : Instability in Rotating Machinery held in Carson City, June 10-14, pp179-194

von Pragenau,G.L., 1982,"Damping Seals for Turbomachinery,"NASA Technical Paper 1987

Table 1. Configuration of Test Seals

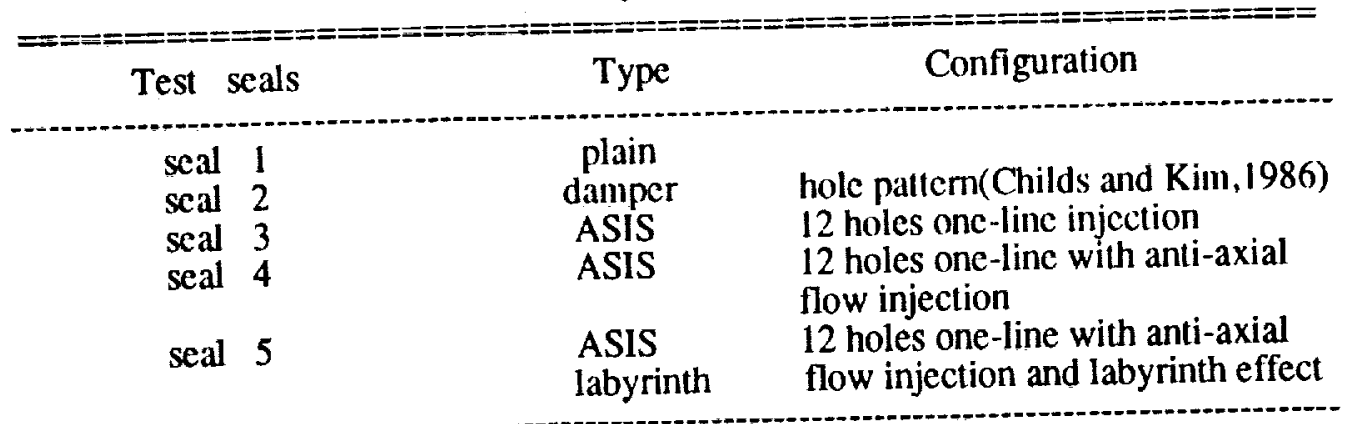

* ASIS : Anti-Swirl Self-Injection Seal 


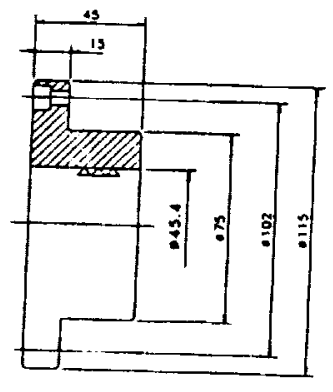

Fig. I(a) Smooth seal insert (seal I)

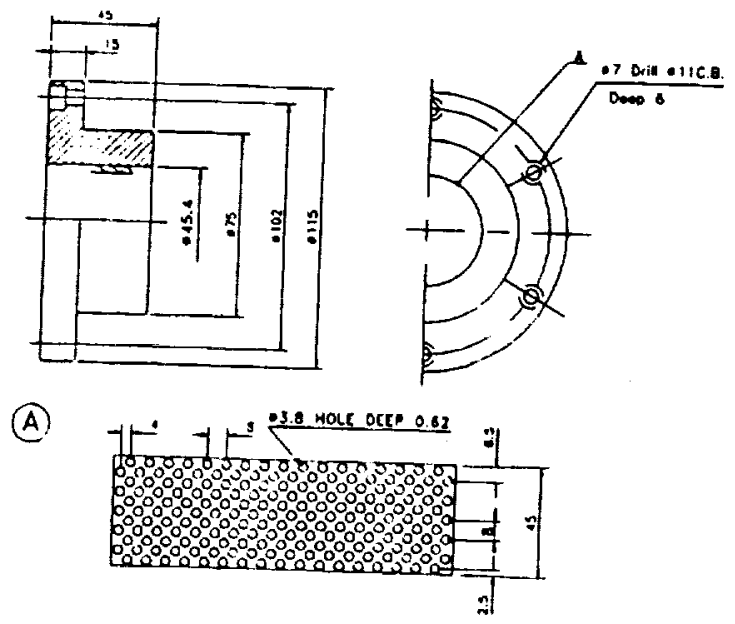

Fig.I(b) Darnper seal insert (seal 2)
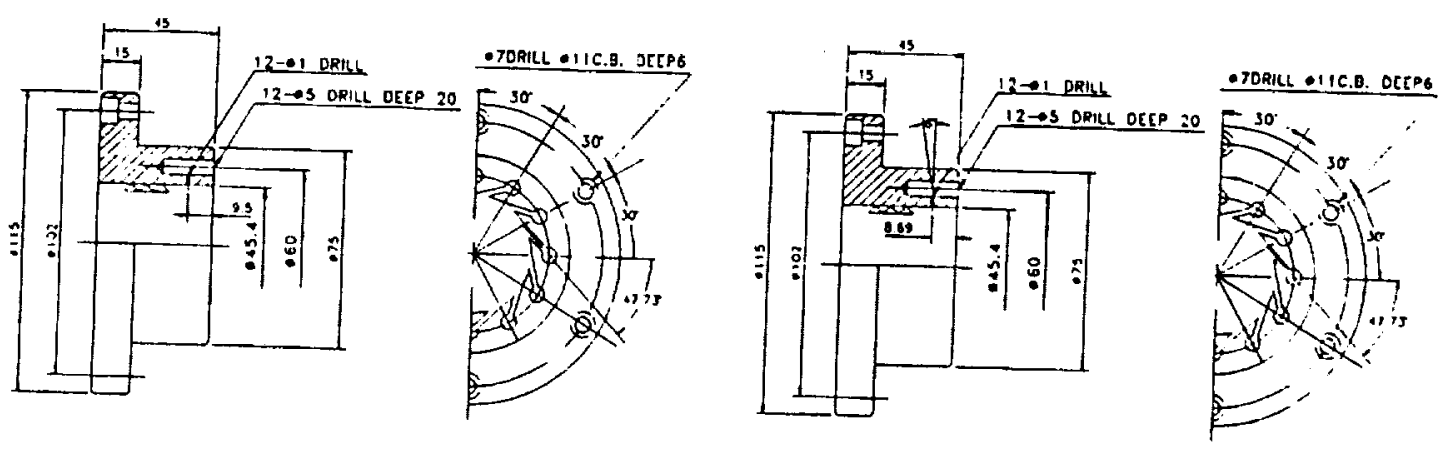

Fig.I (c) Anti-Swirl Self-Injection seal insert (seal 3) Fig.l(d) Anti-Swirl Self-Injection seal insen with anti-axial flow injection (seal 4)

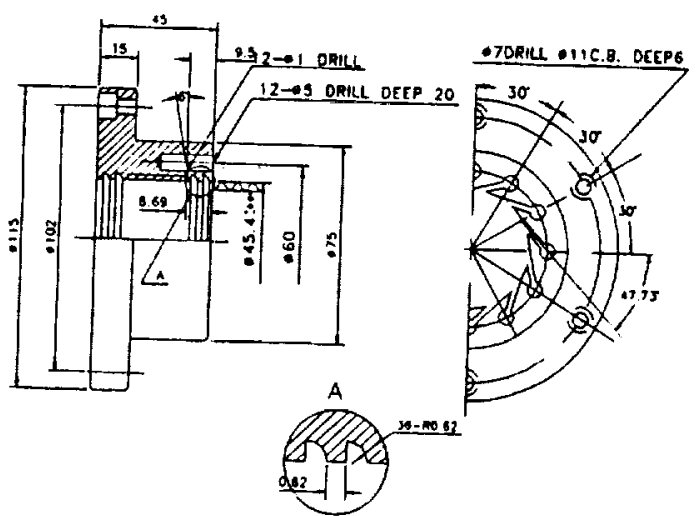

Fig.1(e) Anti-Swirl Self-Injection seal insert with anti-axial flow injection and labyrinth effect (seal 5)

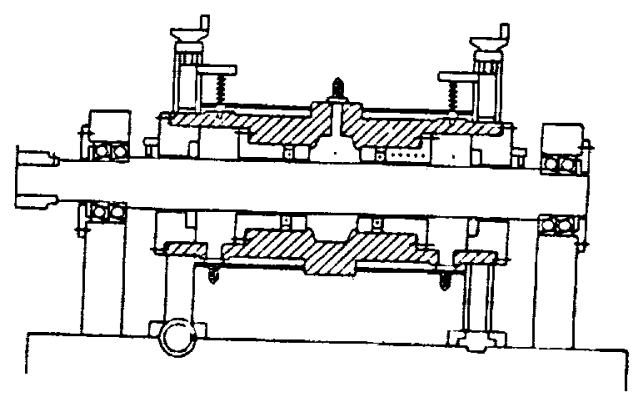

Fig.2 Test apparatus 


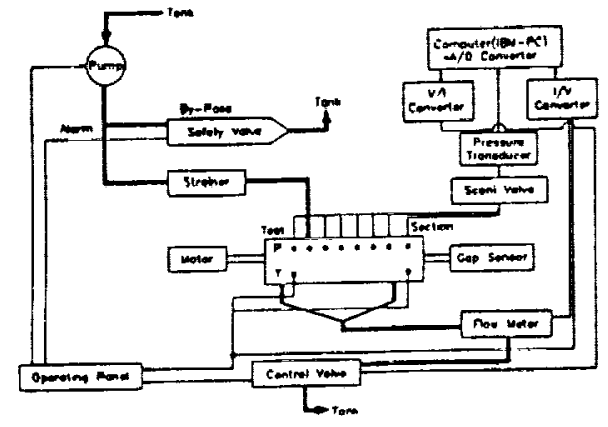

Fig.3 Schematics of the sealing test system

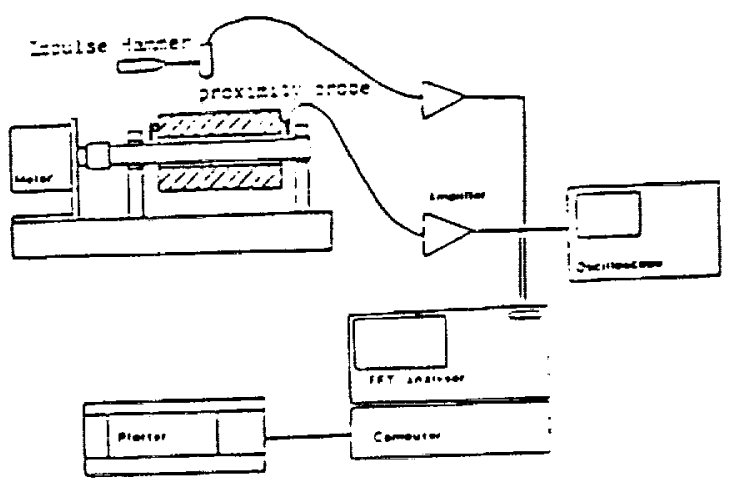

Fig.4 Data acquisition and processing
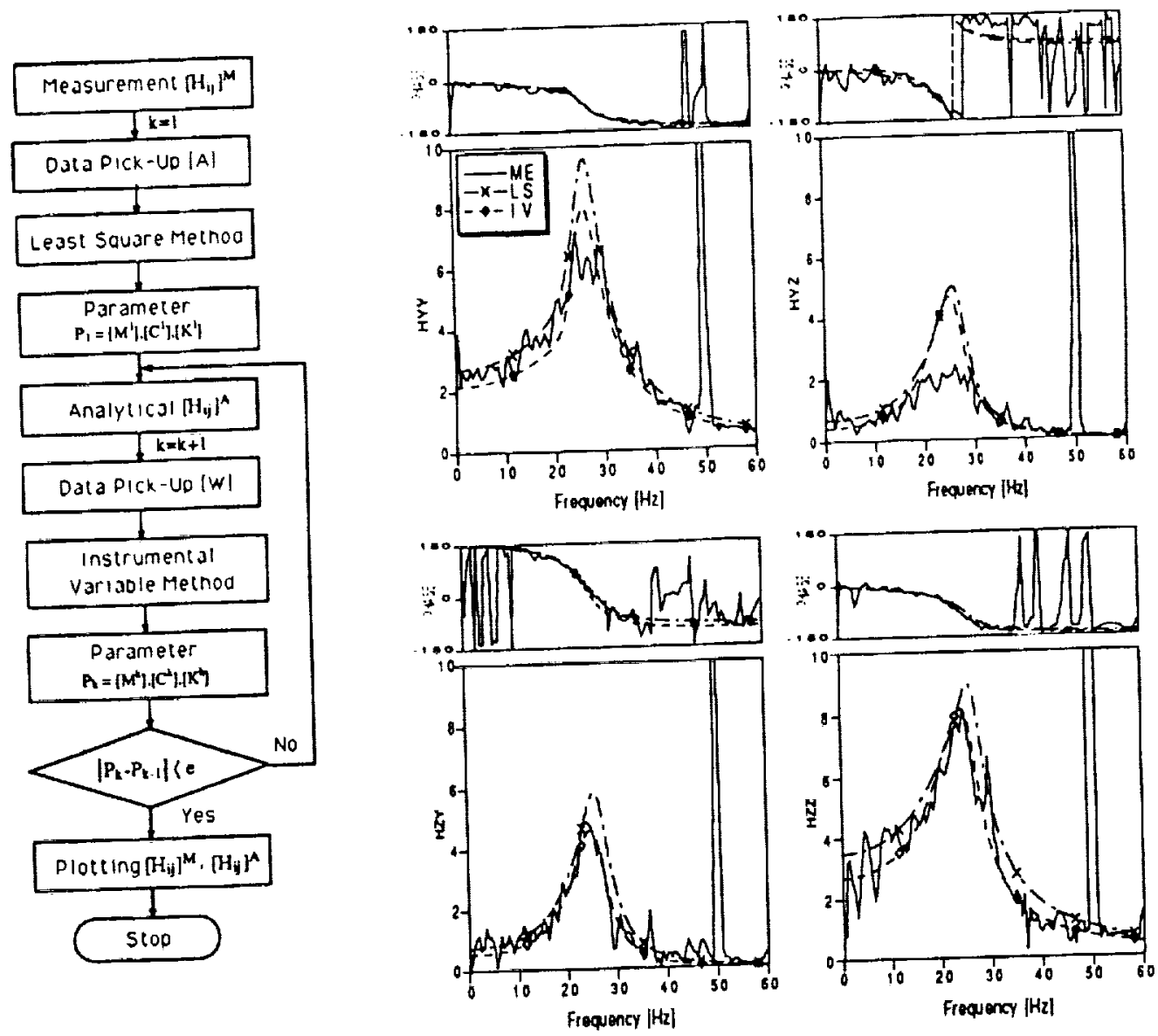

Fig.5 Flow chart of instrumental variable method Fig.6 Example of measured and analytical frequency response functions ( - measured(ME), - X - least square(LS). $-\rightarrow-$ instrumental variable(IV)) 

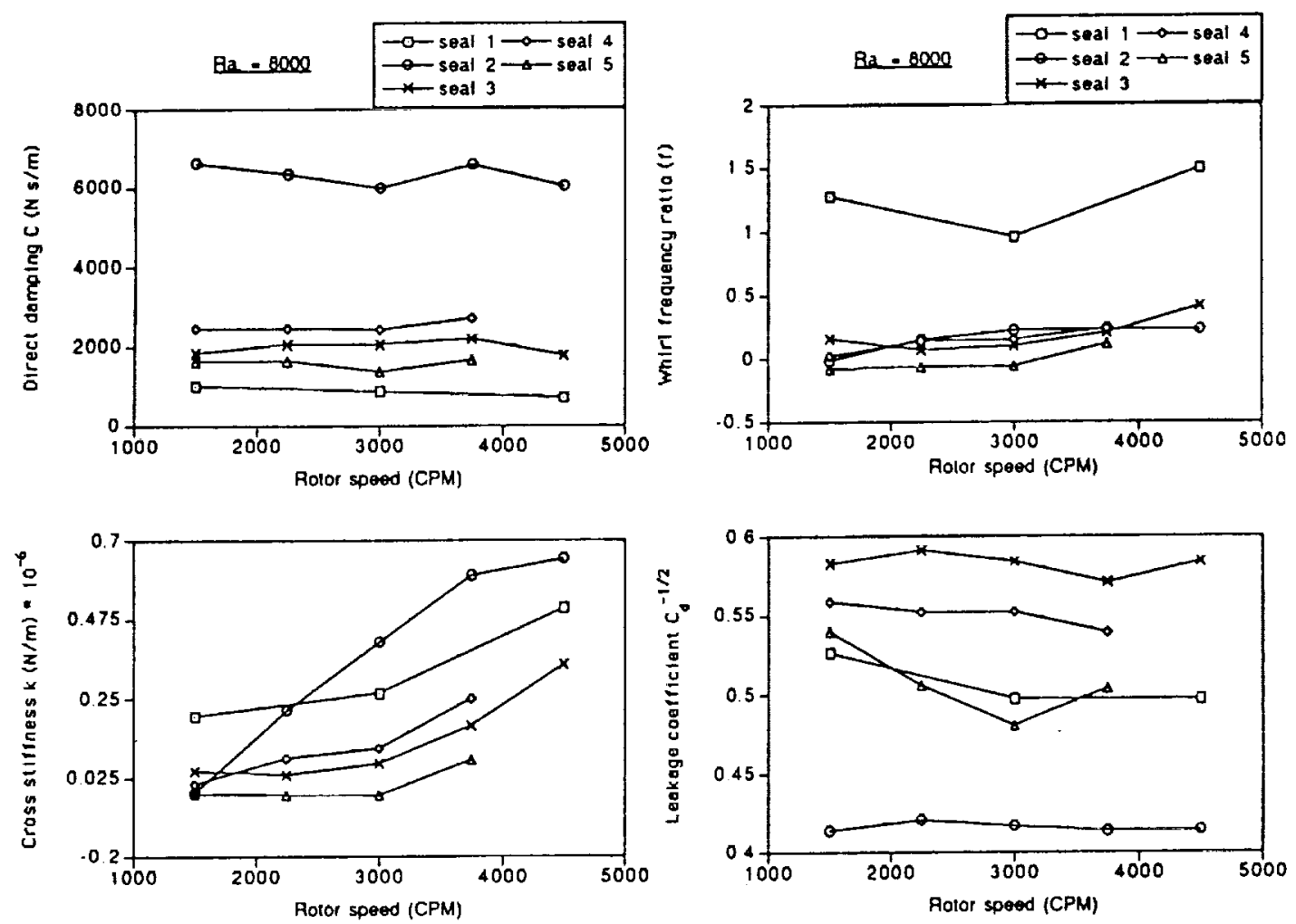

Fig. $7 \mathrm{C}$ and $\mathrm{k}$ versus CPM for the five seals of Table 1 Fig.8 $\mathrm{f}$ and $\mathrm{C}_{d}$ versus $\mathrm{CPM}$ for the five seals of Table:
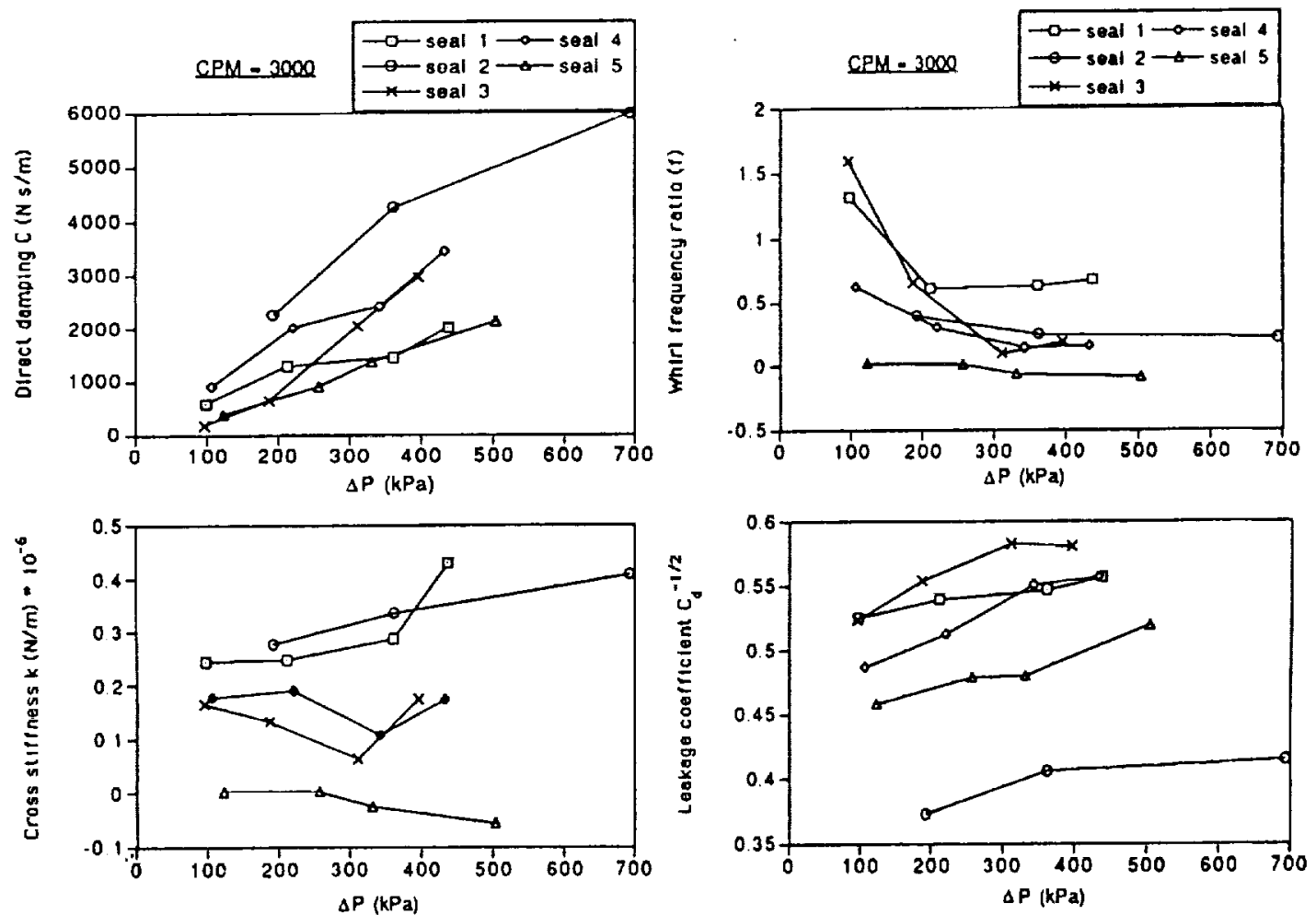

Fig. $9 \mathrm{C}$ and $\mathrm{k}$ versus $\Delta \mathrm{P}$ for the five seals of Table $\mathrm{I}$

Fig. $10 \mathrm{f}$ and $\mathrm{C}_{\mathrm{d}}$ versus $\Delta \mathrm{P}$ for the five seals of Table 1 
